\title{
Poesia e Filosofia. Homenagem a Orides Fontela
}

Só isso cabe ao poeta: ser fiel à voz interior, sem forçar, sem filosofar explicitamente. Deixar que, naturalmente, filosofia e poesia se interpenetrem, convivam, colaborem.

Nasceram juntas, sob a forma do mito, e juntas sempre, sempre colaboram para criar e renovar a nossa própria humanidade.

Orides Fontela

Em A República de Platão, a personagem de Sócrates exclui os poetas do Estado por uma razão prática, qual seja, a de que a poesia seria um tipo de conhecimento pouco confiável e, por isso, danosa para a formação do ser humano. Seu argumento baseia-se, por conseguinte, na ideia de que a poesia não resultaria de uma linguagem totalmente objetiva, ao contrário do que ocorreria, por seu turno, na filosofia. Na visão do pensador grego, a poesia daria margem para que o/a poeta se perca nos caminhos da emoção e dos sentimentos, diferentemente da filosofia, que se pautaria unicamente pela racionalidade de sua linguagem, isto é, por um pensamento claro, baseado em fatos demonstráveis, como ele procura argumentar ao longo do diálogo com o seu interlocutor, Glauco. A poesia trabalharia, portanto, com significados subjetivos que extrapolariam o entendimento guiado pela razão, e, portanto, ela seria inferior ao conhecimento gerado pela filosofia.

Hoje, conquanto seja possível vislumbrar um horizonte menos árido para a poesia essa arte literária tão renegada -, reconhecemos que o ambiente não é completamente favorável. Sabe-se que a poesia possui uma linguagem própria, que não pode ser tratada como inferior nem superior à linguagem da filosofia, e que, ao contrário do que entendemos pelos ideais socráticos expostos em $A$ República, poesia e filosofia podem 
se aproximar, beneficiando-se mutuamente enquanto formas de produção de conhecimento e de pensamento crítico para a sociedade. Numa perspectiva mais ampla, estranhamente ainda causa certa desconfiança em parte da crítica literária quando, em algum estudo, são mescladas essas duas áreas do conhecimento - a literatura e a filosofia. Isso significaria, portanto, que analisar um romance ou um poema a partir de pressupostos filosóficos não seria tão desejável quanto estudá-los a partir de uma fundamentação teórico-crítica advinda somente do campo das Letras. De outro lado, também parece existir alguma resistência da academia no que diz respeito ao estudo da filosofia de um ponto de vista mais poético e, objetivamente, menos cartesiano, como textos filosóficos que têm em seu corpus, objetos literários ficcionais, poéticos e artísticos, e a partir de uma abordagem menos tradicional. Não é de hoje que a Estética é tratada como uma área menor ou menos valorizada dentro da Filosofia, e que, ao contrário, no campo das Artes Visuais e das Letras, ela seja vista como um estudo demasiado complexo, por ser uma disciplina ligada ao campo da Filosofia. Seria o caso de refletirmos, então, se persiste a prevalência de uma mentalidade mais conservadora na área das Humanidades, especialmente no que concerne, aqui, ao diálogo entre a poesia e a filosofia, o qual consideramos, do ponto de vista intertextual e poético, uma aliança extremamente frutífera para ambas as searas. Afinal, é próprio da natureza do estudo estético ter como objetos de investigação a literatura e as artes, e, portanto, a articulação entre o pensamento poético e filosófico tornar-se-ia uma linha de estudo muito profícua tanto na área de Letras como de Filosofia.

Por esse caminho, contrariando os ideais socráticos, a poeta Orides Fontela, denominada pela crítica literária como uma "aristocrata selvagem", quebra a regra prevista em A República de Platão e estabelece em seus poemas singulares a união da poesia com a filosofia, da emoção poética com o pensamento racional. Graduada em Filosofia pela Universidade de São Paulo (1969-1973), Orides de Lourdes Teixeira Fontela (São João da Boa Vista, 1940 - Campos do Jordão, 1998) é uma autora brasileira reconhecida pela crítica especializada e pela academia, considerada uma criadora de poemas de intrincados diálogos com a filosofia. Parte de sua obra já foi traduzida para o francês, o inglês e o catalão, e continua despertando interesse internacional graças à alta qualidade de seus versos e pelas características destoantes de sua obra no espectro da poesia de autoria feminina brasileira. Incontáveis vezes, sua poesia foi classificada como "hermética" e "difícil", denominações que, em grande medida, devem-se à suas influências eminentemente filosóficas, pois a escrita de Orides está intimamente voltada à reflexão, à intertextualidade entre poesia e filosofia. Seus poemas não se encaixam em nenhuma tendência ou padrão de linguagem comumente vistos em poetas mulheres, e excetuando-se, talvez, a influência vinda de Carlos Drummond de Andrade, a poesia oridiana também não encontra semelhança entre os poetas homens de seu tempo. Sem dúvida, dentro de sua geração, a produção oridiana é uma exceção à regra. Dona de um estilo próprio e de uma personalidade bastante autêntica, sua trajetória literária é repleta de posicionamentos 
que, a nosso ver, demarcam território na escrita de autoria feminina desde o início de sua carreira. Isso vai ao encontro, por exemplo, ao fato de que ela fazia questão de refutar a denominação de "poetisa", pois em sua opinião aceitar tal qualificação já seria uma forma de desqualificá-la, no intuito de diminuir ou desconsiderar o trabalho exercido por uma mulher dentro do gênero da poesia. Portanto, Orides Fontela fazia questão de ser chamada de "poeta", porque isso dava a dimensão do seu trabalho com as palavras, com o fazer poético em toda a sua grandeza. Consideramos que esse detalhe linguístico define o posicionamento político, literário e filosófico que permeia toda a sua trajetória de vida e engrandece a sua obra, a qual poderia ser mais lida e prestigiada atualmente.

As origens de Orides Fontela remontam a uma família proletária, muito humilde, de descendência galega. Embora fosse muito apegada ao pai, foi a seu contragosto que Orides assumiu-se feminista. No plano literário, entretanto, a autora evitou criar uma obra que falasse diretamente sobre seus posicionamentos ideológicos, tarefa dificílima para uma mulher de personalidade forte como ela. No entanto, foi um objetivo que a poeta conseguiu alcançar, com vistas a um desejo maior que era o de criar um estilo próprio, uma poética só sua, desvinculada de sua vida pessoal. Em seu trabalho com a poesia, Orides procurou insistentemente desviar de assuntos e temas que remetessem a um tipo e poesia feminina - no sentido pejorativo, ou feminista - voltado ao engajamento. A poesia de tom mais confessional, intimista, de nuances românticas ou eróticas, sempre foi rejeitado por ela, assim como a poesia de extração objetivamente política, conquanto isso não fosse de todo evitável. Sua vida pessoal jamais deveria influenciar a sua produção literária, de acordo com o que ela desejava, porém, até hoje isso atrai a curiosidade do público-leitor e da crítica especializada. Seu objetivo, com esse posicionamento irredutível, era colocar a poesia como o único interesse para quem a lesse ou fosse estudar a sua obra. Por um lado, permitiu que ela criasse uma poesia única, bastante diferenciada e cheia de personalidade, por outro, gerou certa resistência da crítica e do público em torno de si e de seu trabalho. Através da escrita, Orides buscou sempre uma poesia sem rótulos prévios, conquanto não tenha conseguido se desvencilhar completamente do chamado hermetismo, haja vista que suas referências literárias advêm da intertextualidade com a leitura filosófica, e isto não seria um demérito, mas uma qualidade. O resultado dessa influência em sua expressão poética é um trabalho sofisticado em termos de linguagem, exigindo certos conhecimentos prévios, que, todavia, não se torna um empecilho para que qualquer pessoa possa assimilar a sua poesia de uma forma particular, ou seja, a partir de suas próprias referências literárias, formações intelectuais e vivências.

Orides acreditava que não poderia falar sobre coisas que não conhecera ou vivera. Desse modo, sua obra trata e retrata a sua realidade imaginária, e de forma extremamente seletiva: apenas a realidade do seu restrito mundo poético, questionadora do seu fazer, uma poesia voltada para dentro de si mesma, estranha ao mundo exterior. A filosofia entra, portanto, como parte constitutiva e essencial desse repertório literário, influenciando sobremaneira o seu processo criativo. Isso é evidenciado em um ensaio escrito por ela 
em 1997, intitulado "Sobre poesia e filosofia - um depoimento", no qual explica como a filosofia e a poesia se encontram entrelaçadas em seu processo criativo, texto no qual também menciona uma de suas influências filosófico-poéticas mais importantes, a obra do pensador alemão Martin Heidegger, que ela afirma ter lido como poesia.

Nesse sentido, o livro Poesia e Filosofia. Homenagem a Orides Fontela vem ao encontro da necessidade de uma reflexão original acerca das possíveis relações e diálogos entre esses campos do conhecimento, reunindo ensaios intertextuais que tratam da poesia e da filosofia, ao mesmo tempo que realiza uma justa homenagem à obra da poeta paulista Orides Fontela, ainda pouco valorizada e estudada, cuja obra apresenta significativa influência filosófica e se coloca como uma voz poética resistente dentro da escrita feminina brasileira. A publicação é resultado de um evento homônimo realizado na Pontifícia Universidade Católica do Rio de Janeiro, em 2018, que reuniu um grupo importante de pesquisadoras e pesquisadores da obra oridiana, principalmente aquelas(es) que se interessam pela linha de pesquisa que envolve a poesia e a filosofia. Na apresentação do livro, Patrícia Lavelle, uma das organizadoras dessa coletânea de textos em homenagem ao legado poético de Orides Fontela, esclarece:

Em 2018, por ocasião dos vinte anos da morte da poeta Orides Fontela, nos propusemos a refletir sobre o seu legado: uma obra extremamente original no contexto da poesia brasileira contemporânea, combinando objetividade, rigor formal e uma estética despojada com um adensamento filosófico que não encontra paralelos na poesia brasileira de sua época. A partir da reflexão crítica sobre a poética de Orides Fontela, o simpósio que deu origem aos textos reunidos neste volume teve como objetivo mais amplo recolocar em discussão a clássica oposição entre poesia e filosofia. (Lavelle et alii 2019: 7)

Demonstrando que a poesia e a filosofia não estão em oposição, como estabelecia Platão no diálogo entre Sócrates e Glauco, em A República, o livro Poesia e Filosofia. Homenagem a Orides Fontela apresenta leituras especializadas sobre a relação dialética entre poesia e filosofia na obra oridiana. Ele está dividido em três partes distintas, aos quais os artigos foram distribuídos conforme linhas temáticas pré-estabelecidas, quais sejam: 1) Orides (relida) - a qual reúne artigos de seis estudiosas e estudiosos (Patrícia Lavelle, Paulo Henriques Britto, Ivan Marques, Susana Scramin, Renata Sammer e Henrique Estrada), falando diretamente sobre a poesia oridiana e analisando poemas da autora que dialogam com a filosofia; 2) Políticas da poeta - que reúne artigos de quatro pesquisadoras e pesquisadores (Pedro Duarte, Marcia de Sá Cavalcante Schuback, Marcela Oliveira e Alberto Pucheu), cujos assuntos abordados estão relacionados a alguma característica específica da poesia oridiana, como por exemplo, o viés feminista e sua dimensão estética; 3) Poéticas do pensamento - reunindo artigos da pesquisadora Luísa Buarque de Hollanda, Pedro Süssekind e Marc de Launay, que tratam de assuntos diferenciados e que não falam diretamente sobre a obra de Orides Fontela, doravante abordem assuntos que dizem respeito 
ao binômio poesia e filosofia, ao qual a poesia oridiana está intimamente ligada. Nesse total de treze ensaios que constituem o livro, destacaremos, a seguir, os seis textos de autoria das pensadoras participantes, a fim de valorizar a escrita das mulheres na academia. Sem entrar em comparações em relação à escrita masculina, que nesse livro é igualmente de altíssimo nível, verifica-se no trabalho dessas estudiosas, a originalidade de suas propostas e ideias acerca da poesia, da filosofia e da obra oridiana, além da qualidade dos textos e da coerência crítica e teórica que os fundamentam.

Patrícia Lavelle, Susana Scramin e Renata Sammer analisam, em seus textos, poemas específicos de Orides Fontela. Em "O que dá nervo ao poema? Uma releitura de Orides Fontela", Lavelle, apoiada em pressupostos filosóficos e mitológicos, faz uma análise apurada do poema "Kant (relido)", de Orides Fontela, no qual a poeta evoca uma frase do filósofo alemão Immanuel Kant, encontrada na conclusão da Crítica da razão prática (1788), recriando-a de modo surpreendente ao seu mundo poético. Susana Scramin, por sua vez, enfocando diversos poemas de Orides Fontela, analisa-os à luz de uma crítica discursiva feminina no artigo "Aos pulos: deslocamentos na teia com Orides Fontela. Poesia brasileira contemporânea escrita por mulheres", verificando na poesia oridiana uma fala feminina diferenciada que não é jamais explícita, conquanto saibamos que seja a escrita de uma poeta mulher. Renata Sammer, em "Ontologias: sobre as naturezas na poesia de Orides Fontela", verifica em diversos poemas que a autora extrai de um vocabulário poético pautado preferencialmente na natureza, sentidos e ações relacionados à caça e à metamorfose dos seres não-humanos, sugerindo, a partir disso, a existência de uma ontologia (ciência do ser) própria dos seres não-humanos na obra da poeta, numa sintonia com a ecocrítica e a zooliteratura - linhas de estudos que emergem em consonância com a reflexão acerca da importância da preservação do meio ambiente e dos direito dos animais.

Marcia de Sá Cavalcante Schuback e Marcela Oliveira tratam de aspectos políticos na poesia de Fontela. A primeira, em seu artigo "A precisão da poesia: Orides Fontela", trata do aspecto político raramente notado e estudado na escrita oridiana. Para Márcia Schuback, é na precisão das palavras que Orides mostra tanto a sua resistência poética como política. Já a pesquisadora Marcela Oliveira, em "Trança: a poesia e o feminino", volta-se ao interesse de Orides Fontela pela mitologia, tratando a questão do fazer poético como um 'trançar' tipicamente feminino, uma 'trança de versos', como analisa especialmente no poema "Meada", no qual procura verificar o significado do papel da mulher como tecelã de suas próprias ideias e de seu próprio destino.

Para finalizar, Luísa Buarque de Hollanda faz uma análise interessante sobre o pensamento de Aristófanes, dramaturgo da antiguidade grega, certamente menos valorizado que os autores trágicos devido à sua preferência pela comédia, e que se notabilizou, também, por valorizar o papel das mulheres em suas peças. Em "Poética aristofânica", a pesquisadora analisa a peça "As mulheres que celebram as Tesmofórias" como uma "espécie de teoria poética elaborada por Aristófanes" (Hollanda apud Britto et alii 2019: 155), cujo 
valor estaria, de fato, na forma inovadora e eminentemente poética encontrada por Aristófanes para mesclar o riso, a reflexão e a crítica à sua arte de características dionisíacas.

Ressaltamos que todos os textos de autoria masculina participantes da coletânea contribuem positivamente para a sua composição final, porquanto nosso objetivo principal tenha sido o de jogar luz especialmente à escrita crítica das mulheres, devido ao pouco destaque dado às pesquisadoras, pensadoras e escritoras brasileiras no âmbito acadêmico, e que no livro foi bastante enaltecido. Por isso, também, empenhamo-nos em tratar sobre a trajetória e formação acadêmica da poeta Orides Fontela. Trata-se, desse modo, de um recorte a partir de uma afinidade eletiva, com o intuito de valorizar a escrita e o pensamento das mulheres. Contudo, não poderíamos deixar de comentar alguns dos ensaios trazidos pelos pesquisadores e que nos chamaram a atenção. Além disso, recomendamos a leitura dos demais textos dos autores já citados nominalmente. Dentre esses, de autoria masculina que compõem a publicação, destacaremos dois artigos em especial: o de Ivan Marques ("A um passo do anti-pássaro: a poesia de Orides Fontela”), pelo profundo conhecimento que o autor demonstra sobre a obra oridiana, e, principalmente, pela leitura original dos poemas analisados, muito bem fundamentada em termos teórico-críticos; e o de Pedro Duarte ("Há muita poesia na filosofia, sim"), que utilizando uma frase de Orides Fontela como título de seu ensaio, faz uma defesa enfática do diálogo intertextual entre poesia e filosofia, enfocando poemas oridianos de temática eminentemente filosófica como "Maiêutica" e outros, nos quais procura demonstrar o importante papel que a poesia de Orides vem cumprindo em favor da aliança entre essas duas áreas do conhecimento.

Enfim, todos os pesquisadores e pesquisadoras que dessa coletânea de ensaios participaram com seus estudos acerca da obra de Orides Fontela e/ou com reflexões sobre a relação entre a poesia e a filosofia no campo do pensamento estético, trazem-nos, prestando uma digna homenagem ao legado da poeta Orides Fontela e em consonância com a sua produção poética, uma contribuição relevante para os estudos literários e filosóficos, com frescor de ideias e densidade teórico-crítica. Concluímos, por conseguinte, que o livro Poesia e Filosofia. Homenagem a Orides Fontela, a partir de uma proposta interdisciplinar ousada e muito pertinente para a área das Humanidades, apresenta-se como uma excelente opção de leitura e de pesquisa para o público interessado em poesia e filosofia, especialmente àquelas pesquisadoras e aos pesquisadores da obra da poeta Orides Fontela que estejam alinhadas(os) com a defesa da crítica de autoria feminina e feminista, cujos textos objetivamos destacar nesta resenha. O livro poderá interessar, igualmente, aos leitores e às leitoras de filosofia que, buscando uma fonte de pesquisa segura, queiram ampliar e aperfeiçoar seus conhecimentos, principalmente no campo do pensamento estético e da poesia brasileira contemporânea, que consideramos de suma importância para o desenvolvimento de novas formas de pensar a arte e a literatura no contexto histórico contemporâneo. 
NOTA

* Tania Tokairin é graduada em Letras Anglo-Portuguesas e Educação Artística, tem especialização em Literatura Brasileira e mestrado em Estudos Literários pela Universidade Estadual de Londrina. Cursa doutorado em Literatura Brasileira pela Faculdade de Filosofia, Letras e Ciências Humanas da Universidade de São Paulo, onde estuda as obras da poeta Orides Fontela e da artista plástica Mira Schendel. É Bolsista de Doutorado do CNPq.

\section{BIBLIOGRAFIA}

Britto, Paulo Henriques / Pedro Duarte / Henrique Estrada / Patrícia Lavelle (orgs.) (2019), Poesia e Filosofia. Homenagem a Orides Fontela, Belo Horizonte-MG, Relicário. 200 p.

Fontela, Orides (2017), "Sobre poesia e filosofia - um depoimento", in Orides Fontela coleção postal, Rio de Janeiro, Azougue Editorial e Editora Cozinha Experimental, 77-83.

Platão (1973), A República, tradução de J. Guinsburg, São Paulo, Difusão Europeia do Livro. 